\title{
VIEWPOINT
}

\section{Micronutrients and Their Role in Oral Cancer: A Review}

\author{
A Madiyal $^{1}$, SR Shetty ${ }^{2}$, GS Babu ${ }^{1}$
}

\begin{abstract}
Cancer is one of the leading causes of death across the world. Oral cancer is the sixth most common type of cancer in the world. The incidence of oral cancer increases with the increase in the consumption of carcinogens such as tobacco and alcohol as seen in south and southeast Asia. Oral cancer is seen to arise from pre-existing leukoplakia and oral submucous fibrosis. Antioxidants have been hypothesized to be chemopreventive agents for several cancers. Micronutrients such as zinc, copper and selenium, along with antioxidants are required for the production of various enzymes that help prevent DNA damage caused by free radicals.
\end{abstract}

Keywords: Antioxidants, micronutrients, oral cancer, trace elements

\section{Los micronutrientes y su papel en el cáncer oral: una revisión}

\author{
A Madiyal $^{1}$, SR Shetty ${ }^{2}$, GS Babu ${ }^{1}$
}

\begin{abstract}
RESUMEN
El cáncer es una de las principales causas de muerte en todo el mundo. El cáncer oral es el sexto tipo de cáncer más común en el mundo. La incidencia de cáncer oral crece con el aumento del consumo de sustancias cancerígenas como el tabaco y alcohol, como se observa en Asia meridional y sudoriental. Se considera que el cáncer oral surge de una leucoplasia preexistente y una fibrosis submucosa oral. Se sostiene la hipótesis de que los antioxidantes constituyen agentes quimiopreventivos para varios tipos de cáncer. Micronutrientes como el zinc, el cobre y el selenio, junto con los antioxidantes, son necesarios para la producción de varias enzimas que ayudan a prevenir el daño causado por los radicales libres al $A D N$.
\end{abstract}

Palabras claves: antioxidantes, micronutrientes, cáncer oral, elementos de traza

West Indian Med J 2016; 65 (2): 383

\section{INTRODUCTION}

India has one of the highest incidences of oral cancer in the world (1). Oral cancer ranks number one among men and number three among women in India. Oral cancer constitutes $12 \%$ of all cancers in men and $8 \%$ of all cancers in women (2). Oral cancer, the sixth most common cancer worldwide, continues to be the most prevalent cancer related to the consumption of tobacco, alcohol and other carcinogenic products (3). While cancer incidence remain high in south and southeast Asia (traditional high-risk areas), parts of central and eastern
Europe are seeing an alarming increase and now constitute the highest incidence region in the globe (4).

The development of cancer is a multistep process arising from pre-existing potentially malignant lesions. Leukoplakia is the most common pre-cancer, representing $85 \%$ of such lesions (5). Histologically, over $95 \%$ of oral cancers are squamous cell carcinoma $(6,7)$. It has been suggested that a vast majority of oral squamous cell carcinomas in India arise from pre-existing leukoplakia (4).

India is a developing country with one of the most diverse
From: ${ }^{1}$ Department of Oral Medicine and Radiology, AB Shetty Memorial Institute of Dental Sciences, Nitte University, Mangalore, India and ${ }^{2}$ Department of Oral Medicine and Radiology, Gulf Medical University, Ajman, United Arab Emirates.
Correspondence: Dr A Madiyal, AB Shetty Memorial Institute of Dental Sciences, Nitte University, Deralakatte, Mangalore-575018, India. Fax:+919538840189; e-mail: ananyamadiyal@gmail.com 
populations and diets in the world. Cancer rates in India are lower than those seen in Western countries but are rising with increasing migration of the rural population to the cities, increase in life expectancy and changes in lifestyles. In India, rates for oral and oesophageal cancers are some of the highest in the world. In contrast, rates for colorectal, prostrate and lung cancers are among the lowest (8). In India, oral cancer is prevalent in areas where tobacco related practices are observed. For development of oral cancer, tobacco is the single greatest risk factor. This is due to higher concentration of carcinogenic exposure and failure to clean the carcinogens from the mucosal surface (8).

Alcohol, viruses, genetic mechanisms, candida and chronic irritation have modifying effects in the aetiology of cancer. Copper, iron, selenium and zinc are essential for numerous enzymes and, therefore, it is reasonable to assume that variations in serum level of these biochemical markers may be associated with the pathogenesis of oral cancer. The importance of these elements in cancer was reported by Schwartz which opened the door for new diagnostic and therapeutic endeavours in many areas of medicine and specifically in the areas of oncology (9). Epidemiological studies indicate that intervention at an early stage might reduce deaths related to oral carcinoma (9). Immunological and biochemical alterations in the serum of such patients can help not only in early diagnosis and appropriate treatment but also as indicators for prognosis as the disease progresses. Oral cancer is an extremely deadly disease which comprises approximately $2 \%$ of the total malignant tumours in western Europe and North America, but in India it accounts for nearly $50 \%$ of the cancers (10).

Free radicals contain at least one unpaired electron and combine with other molecules to cause cell damage or DNA mutation that leads to carcinogenesis. Antioxidants are produced in the body to counteract this free radical damage and reduce oxidative stress (11). The presence of antioxidants in the body can help prevent various diseases including cancer.

\section{Effect on general health}

Antioxidants such as selenium, vitamin C, vitamin E and carotenoids have been hypothesized as chemopreventive agents for several cancers (11). The essential trace element, selenium, is of fundamental importance to human health. As a constituent of selenoproteins, selenium has structural and enzymatic roles, in the latter context being best known as an antioxidant. An elevated selenium intake may be associated with reduced cancer risk (11). The recommended daily allowance (RDA) of zinc according to the University of Maryland Medical Centre (12) is as follows:

- Men (19 years and older): $11 \mathrm{mg}$

- Women (19 years and older): $8 \mathrm{mg}$

- Pregnant women (14-18 years): $12 \mathrm{mg}$

- Pregnant women (19 years and older): $11 \mathrm{mg}$

- Breastfeeding women (14-18 years): $13 \mathrm{mg}$

- Breastfeeding women (19 years and older): $12 \mathrm{mg}$

It appears that zinc deficiency is prevalent in the develop- ing world and as many as two billion subjects may be growth retarded due to zinc deficiency. It is also an antioxidant and has anti-inflammatory actions. The therapeutic role of zinc in acute infantile diarrhoea, acrodermatitis enteropathica, prevention of blindness in patients with age-related macular degeneration and treatment of common cold has been reported (12).

In HL-60 cells (promyelocytic leukaemia cells), the zinc up-regulates at A20 mRNA, which, via TRAF pathway, decreases NF-B activation leading to decreased gene expression and generation of tumour necrosis factor (TNF- $\alpha$, interleukin-1 and IL-8). Zinc supplementation in young adults and elderly subjects decreased oxidative stress markers and decreased generation of inflammatory cytokines. During the past four decades, a spectrum of clinical deficiency of zinc in human subjects has emerged (13).

Clinical manifestation of zinc deficiency in the developing countries is caused by ingestion of high cereal protein intake, rich in phytate (an organic phosphate compound), which makes zinc unavailable for absorption. Other causes of zinc deficiency include malabsorption syndrome, hyperzincuria as seen in cirrhosis of the liver and sickle cell disease, blood loss due to hookworm infection, and excessive sweating in tropical climates. Manifestations of severe zinc deficiency in humans include bullous pustular dermatitis, alopecia, diarrhoea, emotional disorder, weight loss, intercurrent infections due to cell-mediated immune dysfunctions, hypogonadism in males, neurosensory disorders and problems with healing of ulcers (14).

The manifestations of a moderate deficiency of zinc include growth retardation, rough skin, poor appetite, mental lethargy, delayed wound healing, cell-mediated immune dysfunctions and abnormal neurosensory changes. In experimental human models in whom only a mild deficiency of zinc in males was induced by dietary means, decreased serum testosterone level, oligospermia, decreased natural killer (NK) cell activity, decreased interleukin-2(IL-2) production, decreased thymulin activity, hyperammonaemia, hypogeusia, decreased dark adaptation, and decreased lean body mass were observed (15, 16). Zinc affects multiple aspects of the immune system (17). Zinc is crucial for normal development and function of cells mediating innate immunity, neutrophils and NK cells. Macrophages are also affected by zinc deficiency. Phagocytosis, intracellular killing and cytokine production are affected by zinc deficiency. Zinc deficiency adversely affects the growth and function of $\mathrm{T}$ and $\mathrm{B}$ cells. The role of zinc in modulating oxidative stress has recently been recognized (18-20). The dismutation of oxygen to hydrogen peroxide is catalysed by the enzyme superoxide dismutase (SOD), which contains both copper and zinc. Zinc is known to induce the production of metallothionein which is very rich in cysteine and is an excellent scavenger of ${ }^{\circ} \mathrm{OH}(21)$. Zinc has been shown to inhibit NF-B activation, thus enhancing anticancer therapy (22).

A significant decrease in serum selenium and zinc levels as well as an increase in serum copper level has been shown 
in cancer patients (23). Deficiency manifestation of selenium includes elevated blood mean corpuscular volume (MCV), macrocytosis, unusual hair texture with hypopigmentation (pseudo-albinism), elevated transaminase and creatine kinase activities and profound muscle weakness (24-26).

The possible role of selenium in cancer prevention has been the subject of great interest, largely because it is a key component of the antioxidant enzyme glutathione peroxidase, although it also has many other potentially anticarcinogenic properties, including effects on DNA repair, apoptosis and effects on the immune system (24). Much experimental evidence indicates that high doses of selenium supplementation can inhibit carcinogenesis in many tissue types (25). The realization that several diseases in man are associated with elevated serum copper levels clearly indicates the involvement and likely importance of copper in human health. Copper deficiency may be seen is diseases like Addison's disease, aplastic anaemia, Banti's syndrome, certain carcinomas, central nervous system disorders, collagen diseases, diabetes, Hodgkin's disease, iron deficiency anaemia, hyperthyroidism, leukaemia, malaria, pernicious anaemia, sickle cell anaemia, schizophrenia and thalassaemia.

Total blood copper levels in healthy humans normally range from $1.1-1.5 \mu \mathrm{g} / \mathrm{mL}$. The recommended daily allowance of copper is $2-3 \mathrm{mg} /$ day, although these values can fluctuate with age, exercise and health condition (26).

Availability of copper in various food sources are as follows: Cereals: $22-30 \%$

Meat and fish: $20-30 \%$

Fruits and preserves: $11-16 \%$

Root vegetables: $14-17 \%$

Other vegetables: $10-13 \%$

Beverages: 9-14\%

Milk: 2-3\%

Copper enzymes are widely distributed within the body. They perform several diverse functions including transport of oxygen and electrons, catalysis in oxidation reduction reactions and the protection of the cell against damaging oxygen radicals.

The dismutation of superoxide anions by the copper-zinc enzyme superoxide dismutase renders the potentially damaging superoxide anions less harmful by converting them to less reactive $\mathrm{H}_{2} \mathrm{O}_{2}$. The superoxide anion radical can also result in the formation of the dangerous hydroxyl radical. The targets for these radicals are various cellular components and membranes (27).

Full-blown copper deficiency is rare, as copper is naturally present in many foods. However, many people eat less than the recommended amounts of it. Also, less than $50 \%$ of the copper in the diet is absorbed by the body, which leads to sub-optimal levels. Certain conditions give rise to copper deficiency symptoms. Infants fed on cow's milk, low birthweight infants, and children on low protein diets have been found to be short of copper (28). In the elderly and in people with malabsorption disorders (chronic diarrhoea, Crohn's disease, coeliac disease), nutrients are poorly absorbed which increases the risk of copper deficiency (29). Zinc, iron and copper compete for amino acid carriers that transport them across intestinal walls into the bloodstream. Hence, high doses of any one of these minerals can cause a deficiency in the others. Copper needs sufficient levels of stomach acid for absorption. Regular use of antacids may therefore increase the risk of deficiency (30). Calcium and phosphorus can increase the excretion of copper. Prolonged use of oral contraceptives may also upset copper balance in the body. As copper is involved in many biochemical functions in the body, low levels of it can result in a wide range of disorders (31).

Among the earliest symptoms of copper deficiency are osteoporosis, osteopenia, retarded growth or abnormalities in bone development in low birthweight infants and young children. As copper is needed for the mobilization of iron, deficiency of it is one cause of sideroblastic anaemia, hair loss, impaired immune system that leads to susceptibility to infections, impaired nervous system that may lead to decreased taste sensitivity and lack of physical coordination, inelastic blood vessels that rupture easily, elevated low-density lipoprotein and lower levels, deterioration of heart muscles and irregular heartbeat, breathing difficulties, fatigue and weakness, skin sores, hypothyroidism and Menkes disease (31).

\section{Studies in oral cancer and pre-cancer}

The cellular accumulation of zinc also inhibits mitochondrial terminal oxidation and respiration. In addition to these metabolic effects, zinc accumulation exhibits anti-proliferative effects via its induction of mitochondrial apoptogenesis. Zinc accumulation also inhibits the invasive activities in malignant prostate cells. The anti-proliferative effects and the effects on invasion and migration occur through zinc activation of specific intracellular signalling pathways. Consequently, these effects impose anti-tumour actions by zinc $(32,33)$.

There is now compelling clinical and experimental evidence that zinc is an important factor in prostate cancer and also in other types of cancer. In relation to essential tumour cell activities, the effects of zinc can be categorized as intermediary metabolism and bioenergetic effects, motility and invasive effects, growth and proliferation effects. The actions of zinc on all three activities impose anti-tumour effects in malignant prostate cells and other tumour cells (34-36).

The metabolic decrease in zinc and citrate occurs early in the development of malignancy. Therefore, one must conclude that the metabolic and bioenergetic effects of zinc are incompatible with the ability of the neoplastic cell to conduct its potential malignant activities. To alleviate this imposition, ZIP1 expression is silenced and zinc accumulation is prevented so as to provide the metabolic and bioenergetic requirements of the malignant process. The recent observation that zinc accumulation and ZIP1 protein expression are lower in the RWPE2 tumorigenic prostate cell line compared to the non-tumorigenic RWPE1 cell line supports the role of zinc and ZIP1 as tumour suppressors (37). Zinc insufficiency 
has been associated with the potentiation for development of many tumours and conversely, zinc treatment inhibits development of the tumours. Fong et al reported that zinc deficiency promotes lingual and oesophageal tumorigenesis $(38,39)$. Abnet et al determined that high human tissue zinc concentration was strongly associated with a reduced risk of developing oesophageal squamous cell carcinoma (40). In head and neck cancers, systemic zinc deficiency was associated with increased tumour size and stage of the cancer (41). Recent studies suggest that zinc stimulates the activity of kinases in specific signalling pathways.

Upper aero-digestive tract (UADT) cancer, including oesophageal and tongue tumours, is an important cause of morbidity and mortality worldwide (42). The incidence of UADT cancer is increasing worldwide, including in young adults and those without the known risk factors of tobacco and alcohol use (43). The survival with oral cancer, the major site being the tongue, is poor, with a five-year survival rate of only $10 \%$ (43). Patients with oral cancer have a high mortality rate, because of field cancerization effects that result in second primary tumours, particularly in the oesophagus (44). In addition, patients with oral cancer are frequently zinc deficient (45, 46). Abnet et al established a direct connection between zinc deficiency and human oesophageal squamous cell carcinoma by using X-ray fluorescence spectroscopy to measure zinc, copper, iron, nickel and sulphur in oesophageal biopsy samples obtained from residents in a high ESCC incidence area in China $(39,47,48)$. Zinc replenishment rapidly reverses cell proliferation, stimulates apoptosis, corrects abnormal gene expression in oesophageal epithelium and inhibits tumorigenesis $(37,49,50)$.

A case-control study of oral cancer was conducted in western Washington state between 1983 and 1987. Cases were identified through a population-based registry, and controls were selected by telephone using random digit dialling. Subjects participated in a personal interview, completed a food-frequency questionnaire and submitted clippings from the nails of each great toe for the determination of selenium and zinc concentrations. The odds ratio [OR] for low selenium levels in nail tissue (lowest $25 \%$ of the distribution compared to the upper $75 \%$ ) was 1.4 (95\% confidence interval [CI] 1.0 , 2.2). Likewise, the odds ratio for low zinc levels in nails was $1.6(95 \%$ CI $1.0,2.3)$ but for low dietary zinc, it was $1.0(95 \%$ CI $0.7,1.7)$. Men with oral cancer had lower nail selenium levels than did the controls $(\mathrm{OR}=1.9)$, but women with oral cancer did not $(\mathrm{OR}=0.6)$. Individuals 20 to 39 years of age with oral cancer, in particular, were more likely to have lower selenium levels in nail tissue than controls $(\mathrm{OR}=16.4)$. There was a significant interaction between selenium and ascorbic acid levels which could not be explained by cigarette use. Subjects at greatest risk had low levels of both nutrients. However, since the elements were deposited in the nail matrix close to the date of diagnosis, the differences in the element concentrations between cases and controls may have been a result of the disease (51).
Serum levels of copper and zinc were analysed in 50 patients with oral cancer, 50 patients with oral leukoplakia and 50 patients with oral submucous fibrosis and the values were compared with those of 50 normal healthy adult controls. There was a significant reduction in the serum copper and zinc levels in both oral submucous fibrosis and oral cancer. The copper/zinc ratio was found to be elevated in oral submucous fibrosis and depressed in oral cancer. The ratio may serve as a good indicator for the early detection of oral cancer (52).

Neoplastic diseases and infectious diseases have been reported to lead to changes in zinc metabolism as evidenced by alteration in plasma zinc (53). The presence of these conditions that alter plasma zinc content may lead to accumulative zinc depletion in tissues. It has been observed that deficiencies of zinc in patients with inflammatory and infectious diseases have been attributed to loss of zinc from catabolic tissue and increased urinary excretion of zinc subsequent to its mobilization from interleukins (54). Patients with cancer can excrete as much as three times more zinc than normal patients in their urine. Increased urinary zinc excretion in cancer patients may be linked to immune activation and renal tubular cell dysfunction and skeletal muscle catabolism (55).

In malignancies, the normal zinc-accumulating, citrate-producing epithelial cells are metabolically transformed to citrate-oxidizing cells that lose the ability to accumulate zinc. A genetic alteration in the expression of ZIP1 zinc transporter is associated with this metabolic transformation. These metabolic or genetic relationships have important consequences on citrate related metabolism, bioenergetics, cell proliferation and invasive capabilities of the malignant cells which result in tumour suppressive characteristics. Zinc is critical to these relationships (56). This pattern of change in zinc concentration (ie low plasma zinc and tissue zinc in combination with high urine zinc) is typical of patients with zinc deficiency due to diseases and suggests that a chronic zinc deficiency status may be present in some of these patients as the disease progresses (57).

In a recent Indian study on micronutrient levels in oral cancer and pre-cancer conditions, the following observations were made: serum levels of copper showed gradual increase from pre-cancer to the cancer group as compared to healthy controls which was statistically significant. In oral leukoplakia, significant decrease in selenium level was reported (58). Also, oral cancer showed reduced levels of selenium. In oral leukoplakia, significant decrease in selenium level was reported. Krishnaswamy et al reported decreased selenium levels in both oral and oropharyngeal cancer as compared to matched controls (59).

Some researchers reported an inverse association between pre-diagnostic serum selenium concentrations and the risk of ESCC and gastric cardia cancer (60). Recently, several prospective cohort studies and randomized intervention trials have reported an association between serum selenium concentrations and human chronic disease (61). These studies suggest that selenium, an essential trace element for humans and 
a normal constituent of the diet, is anticarcinogenic (62-65).

Although selenium supplementation showed no protective effect against skin cancer, it was associated with a statistically significant decrease in several secondary endpoints: total cancer mortality $(52 \%)$, total cancer incidence $(39 \%)$ and incidences of lung (44\%), colorectal $(61 \%)$ and prostate $(65 \%)$ cancers $(66,67)$.

\section{CONCLUSION}

Oral cancer is seen to arise from pre-existing leukoplakia and oral submucous fibrosis lesions. Increased incidence of oral cancer is seen in the presence of habits such as tobacco and alcohol consumption. A relative increase in oral cancer is seen in regions with marked nutritional deficiencies coupled with the use of carcinogenic products. Free radicals present in these products cause structural damage to DNA leading to carcinogenesis. Recent evidence suggests that a decrease in serum selenium and zinc levels and an increase in serum copper levels are seen in patients with carcinoma. This suggests that there is a relationship between micronutrients and the development of cancer. Trace elements such as zinc and selenium perform enzymatic and structural roles along with vitamin $\mathrm{C}$, vitamin E and metals like copper to prevent DNA damage. Decrease in serum selenium and zinc levels in oral carcinoma patients can be attributed to their role as powerful antioxidants. Zinc and selenium supplements given to patients with head and neck cancer are seen to decrease the progression of cancer. Prevention and treatment of head and neck cancer may be possible with better understanding of the role of antioxidants and micronutrients in the development of the disease. Further research is necessary to confirm the role of micronutrients in the treatment of cancer.

\section{REFERENCES}

1. Hamada GS, Bos AJ, Kasuga H, Hirayama T. Comparative epide miology of oral cancer in Brazil \& India. Tokai J Exp Clin Med 1991; 16: 63-72.

2. Sankaranarayanan R. Oral cancer in India: An epidemiologic and clinical review. Oral Surg Oral Med Oral Path 1990; 69: 325-30.

3. Daftary DK, Murti PR, Bhonsle RR, Gupta PC, Mehta FS, Pindborg JJ. Risk factors and risk areas of the world. In: Johnson N W, editor. Oral Cancer: the detection of patients and lesions at risk. Cambridge (UK): Cambridge University Press. 1991. p. 29-63.

4. Gupta PC. Leukoplakia and effect of oral cancer. J oral pathol med 1989; 18: 11.

5. Bouquot JE, Whitaker SB. Oral Leukoplakia rationale for diagnosis and prognosis of its clinical subtypes or phases. Quintessence Int 1994; 25: $133-40$.

6. Chen J, Eisenberg E. Changing trends in oral cancer in United States 1935-1985. A Connecticut study. J Oral Maxillofac Surg 1991; 49: $1152-8$.

7. Ostman J, Anneroth E. Malignant Oral Tumors in Sweden 19621989. An Epidemiological Study. Eu J Cancer and Oral Oncology 1995; 8: $106-12$.

8. Quarri D, Adams G, Shons Alan, Browne G. In: Head and Neck Cancer: Clinical decisions and management principles. 1997. p. 219-20.

9. Schwartz MK. Role of trace elements in cancer. Cancer res 1975; 35: 3481-7.

10. Salinas FA, Wee KH, Silver HK. Clinical relevance of immune complexes associated antigen and antibody in cancer. In: Immune com- plexes and human cancer. Penguin publishing Corp. 1985; 62.

11. Jayaprakash V, Marshall JR. Selenium and other antioxidants for chemoprevention of gastrointestinal cancer. Best Pract Res Clin Gastroenterol 2011; 25: 507-18.

12. Steven D, Ehrlich NMD. Zinc. [Reviewed 2011 June 30] Available from: http://www.umm.edu/altmed/articles/zinc-000344.htm

13. Prasad AS. Clinical spectrum of human zinc deficiency. In: Prasad AS, editor. Biochemistry of zinc. New York: Plenum Press; 1993. p. 219-58.

14. Prasad AS, Meftah S, Abdallah J, Kaplan J, Brewer GJ, Bach JF. Serum thymulin in human zinc deficiency. J Clin Invest 1988; 82: 1202-10.

15. Beck FWJ, Kaplan J, Fine N, Handshu W, Prasad AS. Decreased expression of CD73 ecto-5-nucleotidase in the CD8+ subset is associated with zinc deficiency in human patients. J Lab Clin Med 1997; 130: 147-56.

16. Beck FWJ, Prasad AS, Kaplan J, Fitzgerald JT, Brewer GJ. Changes in cytokine production and $\mathrm{T}$ cell subpopulations in experimentally induced zinc-deficient humans. Am J Physiol 1997; 272: E1002-7.

17. Shankar AH, Prasad AS. Zinc and immune function: The biological basis of altered resistance to infection. Am J Clin Nutr 1998; 68: 447S-63S.

18. Castro L, Freeman BA. Reactive oxygen species in human health and disease. Nutr 2001; 17: 161-5.

19. Davis JN, Kucuk O, Djuric Z, Sarkar FH. Soy isoflavone supplementation in healthy men prevents NF-kappa B activation by TNF-alpha in blood lymphocytes. Free Radic Biol Med 2001; 30: 1293-302.

20. Lachance PA, Nakat Z, Jeong W. Antioxidants: An integrative approach. Nutr 2001; 17: 835-8.

21. Banister J, Banister W, Rotilio G. Aspects of structure, functions and application of superoxide dismutase. CRC Crit Rev Biochem 1987; 22: $111-80$.

22. Uzzo RG, Leavis P, Hatch W, Gabai VL, Dulin N, Zvartau N. Zinc inhib its nuclear factor-B activation and sensitizes prostate cancer cells to cytotoxic agents. Clin Can Res 2002; 8: 3579-83.

23. Burk RF. Selenium and cancer: Meaning of serum selenium levels. J Nutr 1986; 116: 1584-6.

24. Combs GFJ, Gray WP. Chemopreventive agents: Selenium. Pharmacol Therap 1998; 79: 179-92.

25. Harris ED. Copper in human and animal health.. In: Rose J, editor. Trace Elements in Health: a review of current issues, 1st ed. Butterworth and Co. publishers; 1983. p. 44-73.

26. Underwood EJ. Copper. In: Trace elements in humans and animal nutrition, 4th ed. New York: Academic Press; 1977. p. 56-233.

27. Klevay LM. Dietary copper and the copper requirement of man. In: Kirchgessner M, editor. Trace Element Metabolism in Man and Animals; 1978. p. 307-10.

28. Uauy, Ricardo, Olivarez M, Gonzales M. Essentiality of copper in humans. Am. J Clin Nutr 1989; 67: 952-9.

29. Trumbo P, Yates AA, Schlicker S, Poos M. Dietary reference intakes: vitamin $\mathrm{A}$, vitamin $\mathrm{K}$, arsenic, boron, chromium, copper, iodine, iron, manganese, molybdenum, nickel, silicon, vanadium and zinc. J Am Diet Assoc 2001; 101: 294-301.

30. Rigs BL, Melton LJ III. Involutional osteoporosis. N Engl J Med 1986; 314: 1676-86.

31. Klevay LM. Myelodysplasia, myeloneuropathy and copper deficieny. Mayo clinic proceedings 2006; 81: 131-3.

32. Dhar NK, Goel TC, Dube PC, Chowdhury AR, Kar AB. Distribution and concentration of zinc in the subcellular fractions of benign hyperplastic and malignant neoplastic human prostate. Exp Mol Pathol 1973; 19: $139-42$.

33. Maret W. Oxidative metal release from metallothionein via zinc-thiol/ disulfide interchange. Proc Natl Acad Sci U S A 1994; 91: 237-41.

34. Ye B, Maret W, Vallee BL. Zinc metallotheinin imported into liver mitochondria modulates respiration. Proc Natl Acad Sci U S A 2001; 98: 2317-22.

35. Costello LC, Guan Z, Franklin RB, Feng P. Metallotheionin can function as chaperone for zinc uptake transport into prostate and liver mitochondria. J Inorg Biochem 2004; 98: 664-6.

36. Huang L, Kirschke CP, Zhang Y. Decreased intracellular zinc in human tumorigenic prostate epithelial cells: a possible role in prostate cancer progression. Cancer Cell Int 2006; 6: 10. 
37. Fong LY, Nguyen VT, Farber JL. Esophageal cancer prevention in zincdeficient rats: rapid induction of apoptosis by replenishing zinc. J Natl Cancer Inst 2001; 93: 1525-33.

38. Fong LY, Jiang Y, Farber JL. Zinc deficiency potentiates induction and progression of lingual and esophageal tumours in p53-deficient mice. Carcinogenesis 2006; 27: 1489-96.

39. Abnet CC, Lai B, Qiao YL, Vogt S, Luo XM, Taylor PR et al. Zinc concentration in esophageal biopsy specimens measured by $\mathrm{X}$-ray fluorescence and esophageal cancer risk. J Natl Cancer Inst 2005; 97: 301-6.

40. Prasad AS, Beck FW, Doerr TD, Shamsa FH, Penny HS, Marks SC et al. Nutritional and zinc status of head and neck cancer patients: an interpretive review. J Am Coll Nutr 1998; 17: 409-18.

41. Parkin DM, Bray F, Ferlay J, Pisani P. Estimating the world cancer burdenGlobocan 2000. Intl J Cancer 2001; 94: 153-6.

42. Moore SR, Johnson NW, Pierce AM, Wilson DF. The epidemiology of tongue cancer: a review of global incidence. Oral Dis 2000; 6: 75-84.

43. Slaughter DP, Southwick HW, Smejkal W. Field cancerization in oral stratified squamous epithelium; clinical implications of multicentric origin. Cancer 1953; 6: 963-8.

44. Makuuchi H, Machimura T, Shimada H, Mizutani K, Chino O, Kise Y et al. Endoscopic screening for esophageal cancer in 788 patients with head and neck cancers. Tokai J Exp Clin Med 1996; 21: 139-45.

45. Doerr TD, Prasad AS, Marks SC, Beck FW, Shamsa FH, Penny HS et al. Zinc deficiency in head and neck cancer patients. J Am Coll Nutr 1997; 16: $418-22$.

46. Kleier C, Werkmeister R, Joos U. Zinc and vitamin A deficiency in diseases of the mouth mucosa. Mund Kiefer Gesichtschir 1998; 2: 320-5.

47. Yang CS. Research on esophageal cancer in China: a review. Cancer Res 1980; 40: 2633-44.

48. Van Rensburg SJ. Epidemiologic and dietary evidence for a specific nutritional predisposition to esophageal cancer. J Natl Cancer Inst 1981; 67: $243-51$.

49. Fong LY, Zhang L, Jiang Y, Farber JL. Dietary zinc modulation of COX-2 expression and lingual and esophageal carcinogenesis in rats. J Natl Cancer Inst 2005; 97: 40-50.

50. Liu CG, Zhang L, Jiang Y, Chatterjee D, Croce CM, Huebner K et al. Modulation of gene expression in precancerous rat esophagus by dietary zinc deficit and replenishment. Cancer Res 2005; 65: 7790-9.

51. Varghese I, Sugathan CK, Balasubramoniyan G, Vijayakumar. Serum Copper and Zinc Levels in Premalignant and Malignant Lesions of the Oral Cavity. Oncology 1987; 44: 224-7.
52. Rogers MA, Thomas DB, Davis S, Weiss NS, Vaughan TL, Nevissi AE. A case control study of oral cancer and pre-diagnostic concentrations of selenium and zinc in nail tissues. Int J Cancer 1991; 48: 182-8.

53. Vallee BL, Wacker WE, Bartholomay AF, Hotch FC. Zinc metabolism in hepatic dysfunction, serum zinc concentration in laennec's cirhossis and their validation by sequential analysis. New Engl J Med 1957; 257: 1055.

54. Prasad AS. Clinical manifestations of zinc deficiency. Ann Rev Nutr 1985; 4: 591-8.

55. Melichar B, Mali F, Jandik P, Maliova E, Vavrova J, Mergancova JK et al. Increased urinary zinc excretion in cancer patients is linked to immune activation and renal tubular cell dysfunction. Biometals 1995; 8: $205-8$.

56. Costello LC, Franklin RB. The clinical relevance of the metabolism of prostrate cancer; zinc and tumor suppression; connecting the dots. Mol Cancer 2006; 15: 5-17.

57. Melichar B, Jandik P, Tichy M, Malir F, Mergancova J, Voboril Z. Urinary zinc excretion and acute phase response in cancer patients. Clin Investig 1994; 72: 1012-14.

58. Khanna SS, Karjodkar FR. Circulating immune complex and trace elements (copper, iron and selenium) as markers in oral precancer and cancer: a randomized, controlled clinical trial. Head Face Med 2006; 2: 33.

59. Vijaykumar T. Circulating immune complexes as biological marker for solid tumors. J Exp Clin Cancer Res 1986; 5: 3.

60. Combs GF Jr. Impact of selenium and cancer-prevention findings on the nutrition-health paradigm. Nutr Cancer 2001; 40: 6-11

61. Combs GF Jr, Clark LC, Turnbull BW. An analysis of cancer prevention by selenium. Biofactors 2001; 14: 153-9.

62. Combs GF Jr. Considering the mechanisms of cancer prevention by selenium. Adv Exp Med Biol 2001; 492: 107-17.

63. Combs GF Jr. Selenium in global food systems. Br J Nutr 2001; 85: 517-47.

64. Ganther HE. Selenium metabolism and mechanisms of cancer prevention. Adv Exp Med Biol 2001; 492: 119-30.

65. Lu J. Apoptosis and angiogenesis in cancer prevention by selenium. Adv Exp Med Biol 2001; 492: 131-45.

66. Clark LC, Combs GF Jr, Turnbull BW, Slate EH, Chalker DK, Chow J et al. Effects of selenium supplementation for cancer prevention in patients with carcinoma of the skin. A randomized controlled trial. Nutritional Prevention of Cancer Study Group. JAMA 1996; 276: 1957-63.

67. Clark LC, Dalkin B, Krongrad A, Combs GF Jr, Turnbull BW, Slate EH et al. Decreased incidence of prostate cancer with selenium supplementation: results of a doubleblind cancer prevention trial. Br J Urol 1998; 81: 730-4. 